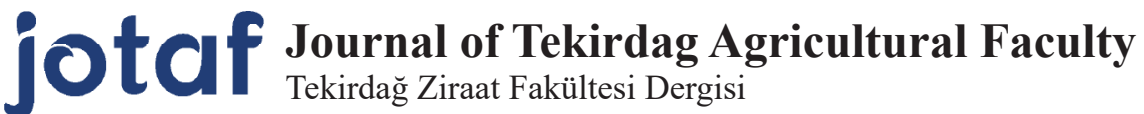

\section{Tekirdağ Koşullarında Patlıcan Bitkisinin Su Kullanım Özelliklerinin Belirlenmesi*}

\author{
Determination of Water Use Characteristics of Eggplant in Tekirdağ Conditions
}

\author{
Seda Devrim YENIGÜN ${ }^{1}$, Tolga ERDEM ${ }^{2 * *}$
}

\begin{abstract}
$\ddot{O} \mathbf{z}$
Tekirdağ koşullarında farklı damla sulama uygulamaları altında patlıcan bitkisinin su kullanımına, verim ve gelişme parametrelerine etkilerinin incelendiği çalışma, 2015 ve 2016 yıllarında yürütülmüştür. Araştırmada, 5 gün sulama aralığında A sınıfı buharlaşma kabından ölçülen buharlaşma değerlerinin \%50, 75, 100 ve 125 'inin uygulandığı dört farklı sulama suyu uygulaması gerçekleştirilmiştir. Araştırmanın ilk yılında tüm deneme konularına 20 kez sulama uygulaması ile birlikte 283.0 ile $693.0 \mathrm{~mm}$ arasında, denemenin ikinci yılında ise $19 \mathrm{kez}$ sulama uygulaması ile birlikte 293.0 ile $693.0 \mathrm{~mm}$ sulama suyu uygulanmıştır. Araştırma sonucunda, deneme konularında bitki büyüme mevsimi boyunca ölçülen bitki su tüketimi değerleri 2015 yılında 4662 ile $837.0 \mathrm{~mm}, 2016$ yılında ise 411.7 ile $797.1 \mathrm{~mm}$ arasında uygulanan sulama suyu miktarlarına bağlı olarak değişmiştir. Günlük bitki su tüketimi değerleri ise 2015 yılında 1.6 ile $9.5 \mathrm{~mm} /$ gün ve 2016 y1lında 3.0 ile $9.7 \mathrm{~mm} /$ gün arasında değişmiştir. Deneme konularından elde edilen toplam pazarlanabilir verim değerleri, birinci y1l 33.4 ile $47.6 \mathrm{t} / \mathrm{ha}$, ikinci yıl ise 21.80 ile $31.90 \mathrm{t} /$ ha arasında değişmiştir. Verim değerleri üzerine yapılan istatistiksel sonuçlar dikkate alındığında, denemenin her iki yılında da önemli farklar elde edilmemiştir. Sulama suyu kullanım randımanı (IWUE) değerleri denemenin ilk yılında 6.86 ile $11.80 \mathrm{~kg} / \mathrm{m}^{3}$, denemenin ikinci yılında ise 4.49 ile $7.44 \mathrm{~kg} / \mathrm{m}^{3}$ arasında değişmiştir. Su kullanım randımanı (WUE) değerleri ise denemenin ilk yılında 5.68 ile $7.16 \mathrm{~kg} / \mathrm{m}^{3}$, denemenin ikinci yılında ise 3.83 ile $5.30 \mathrm{~kg} / \mathrm{m}^{3}$ arasında değişmiştir. Sulama randımanı değerleri arasında yapılan istatistiksel analizlerde A sınıfı buharlaşma kabından ölçülen buharlaşma değerlerinin \%50’sinin uygulandığı deneme konusunun ön plana çıktığı görülmüştür.
\end{abstract}

Anahtar Kelimeler: Bitki su tüketimi, vejetatif gelişme parametreleri, su kullanım randımanı (WUE), patlıcan

\begin{abstract}
The study on the effects of different irrigation practices under drip irrigation method on eggplant water use, yield and vegetative parameters was carried out under Tekirdag conditions in 2015 and 2016. Four different irrigation water amounts with 5 days interval applied based on a ratio of Class A pan evaporation as 50,75, 100 and $125 \%$ were created in the research. In the first year of the study all treatments with irrigation water application 20 times between 283.0 and $693.0 \mathrm{~mm}$ with irrigation application, 19 times of 293.0 and $693.0 \mathrm{~mm}$ of irrigation water in the second year and was applied. As a result of this study, the seasonal evapotranspiration in the treatments during the measurement period varied from 466.2 and $837.0 \mathrm{~mm}$ in 2015 and from 411.7 and $797.1 \mathrm{~mm}$ in 2016 depend on irrigation water applied. The daily crop evapotranspiration varied between 1.6 and $9.5 \mathrm{~mm}$ /day in 2015 and between 3.0 and $9.7 \mathrm{~mm}$ /day in 2016 . Total marketable yield values obtained from the experiment subjects ranged between 33.4 and $47.6 \mathrm{t} \mathrm{ha}^{-1}$ in the first year and 21.80 to $31.90 \mathrm{t} \mathrm{ha}^{-1}$ in the second year. Considering the statistical analyses on yield and yield component values, no significant differences were obtained in both years of the experiment. Irrigation water use efficiency (IWUE) values ranged from 6.86 to $11.80 \mathrm{~kg} \mathrm{~m}^{-3}$ in the first year of the experiment and from 4.49 to $7.44 \mathrm{~kg} \mathrm{~m}^{-3}$ in the second year of the experiment. Water use efficiency (WUE) values were between 5.68 and $7.16 \mathrm{~kg} \mathrm{~m}^{-3}$ in the first year of the experiment and 3.83 to $5.30 \mathrm{~kg} \mathrm{~m}^{-3}$ in the second year of the experiment. In the statistical analyses among the efficiency values, $50 \%$ of the evaporation values measured from the class A evaporation pan were suggested.
\end{abstract}

Keywords: Evapotranspiration, vegetative growth parameters, water use efficiency (WUE), eggplant

\footnotetext{
${ }^{1}$ Seda Devrim Yenigün, Nezahat Gökyiğit Botanik Bahçesi, İstanbul. E-mail: sedadevrimyenigun91@gmail.com (D) OrcID: 0000-0002-74022312

2**Sorumlu Yazar/Corresponding Author: Tolga Erdem, Tekirdağ Namık Kemal Üniversitesi Ziraat Fakültesi Biyosistem Mühendisliği Bölümü, TEKIRDAĞ. E-mail: terdem@nku.edu.tr, (iD OrcID: 0000-0002-5887-9586

Atıf/Citation: Yenigün, S.D., Erdem, T. Tekirdağ koşullarında patlıcan bitkisinin su kullanım özelliklerinin belirlenmesi. Tekirdağ Ziraat Fakültesi Dergisi, 16(2), 221-231.

*Yüksek Lisans tezinden üretilmiştir

(CBu çalışma Tekirdağ Namık Kemal Üniversitesi tarafından Creative Commons Lisansı (https://creativecommons.org/licenses/by-nc/4.0/) kapsamında yayınlanmıştır. Tekirdağ 2019
} 


\section{Extendend Summary}

The Thrace Region is one of the most important agricultural regions of our country, and it provides $35 \%$ of the sunflower production and $12 \%$ of the wheat production. However, the search for alternative plant patterns has accelerated due to the decrease in agricultural areas due to rapid industrialization in the region and the necessity of increasing production from the unit area. Although the sunflower and wheat cultivation are planted in dry conditions in the region, the unit area yields obtained from both plants are higher than the country average due to the regular spring rains. Furthermore, in the period between the two plant growing periods, especially after the wheat harvest in June-July, in the agricultural lands which are empty for approximately 8 months until sunflower planting in April-May, plant alternatives that can be grown under the irrigation conditions should be produced and the usability of intensive farming should be revealed in the region. As one of these alternatives, vegetable cultivation may be preferred due to its shortness of cultivation period and its marketability. Eggplant is as valuable as other vegetables in terms of vitamins and minerals. For this reason, it has great economic value in many countries including our country. According to statistics, the third important vegetable after potato and tomato production in the Solanaceae family (Doğanlar et al. 2002, Çolak et al. 2017). Turkey has an important place in the production of eggplant in the countries with 880 thousand tons. Turkey is in third place in terms of production among the countries which made eggplant production and meets $3 \%$ of the world production. Eggplant production in all regions of our country, although the intensity, according to 2015 data, the highest percentage of eggplant production in the Mediterranean region with 392000 tons (Anonymous, 2015).

The study was conducted to investigate the effects of different irrigation water applications on the eggplant under the drip irrigation method. Four different irrigation water applications were carried out with 50, 75, 100 and $125 \%$ of the evaporation values measured from the Class A pan. The irrigation numbers applied in 2015 and 2016 were different depending on the amount of irrigation water and measured plant water consumption. In the first year of the study, irrigation water was applied between 283.0 and $693.0 \mathrm{~mm}$ with irrigation application for 20 times and irrigation water was applied between 293.0 and $711.5 \mathrm{~mm}$ with 19 times irrigation application in the second year. The amounts of irrigation water applied between the experimental subjects varied according to the percentage of application of the evaporation values measured from the Class A pan. The highest irrigation water applications were carried out to the treatment subject where $125 \%$ of the evaporation values measured from Class A pan were applied. Seasonal eggplant evapotranspiration values measured from experimental subjects during the whole growing season have been changed according to the amount of irrigation water applied between 466.2 and 837.0 $\mathrm{mm}$ in 2015 and between 411.7 and $797.1 \mathrm{~mm}$ in 2016. As the amount of irrigation water applied increased, the water consumption values of the plants increased. Daily plant evapotranspiration values, which are an important parameter in terms of irrigation time planning, between 1.6 and $9.5 \mathrm{~mm} /$ day in 2015 and 3.0 to $9.7 \mathrm{~mm} / \mathrm{day}$ in 2016 , depending on the amount of irrigation water applied.

The relationship between the efficiency of irrigation water and measured evapotranspiration is explained by using irrigation water use efficiency and water use efficiency. Irrigation water use efficiency (IWUE) values ranged from 6.86 to $11.80 \mathrm{~kg} \mathrm{~m}^{-3}$ in the first year of the experiment and from 4.49 to $7.44 \mathrm{~kg} \mathrm{~m}^{-3}$ in the second year of the experiment. Water use efficiency ( $W U E$ ) values in the first year of the experiment ranged between 5.68 and $7.16 \mathrm{~kg} \mathrm{~m}^{-3}$ and in the second year of the experiment ranged from 3.83 to $5.30 \mathrm{~kg} \mathrm{~m}^{-3}$. Both of the yield values obtained in the first year of the experiment were higher due to the higher yield values. In the statistical analysis of the yield values, the difference between the irrigation water efficiency (IWUE) values was statistically significant at $\mathrm{p}<0.01$ level in both years. As a result of the statistical analyses, it was observed that $50 \%$ of the evaporation values measured from Class A pan were suggested. 
Doğal kaynakların gün geçtikçe azalması, her alanda olduğu gibi tarımda da yeni arayışları ortaya çıkarmaktadır. Sanayileşme ve kentleşme nedeniyle tarım alanları azalmakta buna karşın bu alanlardan beslenecek insan nüfusu hızlı bir biçimde artmaktadır. Bu nedenle, yürütülen araştırmalar birim alandan elde edilecek verimi maksimuma çıkarmak üzerine yoğunlaşmaktadır. Diğer tarımsal işlemlerin yanı sıra maksimum verim eldesin de sulamanın önemi ortadadır. Fakat günümüze kadar uygulanan bilinçsiz sulamalar ve mevcut suyun tarım dışındaki diğer alanlarda kullanımının artması nedeniyle sulama için kullanılacak su miktarında da azalmalar başlamıştır. Böylece, dünyada ve ülkemizde, mevcut kısıtlı su ile birim alandan elde edilecek verimin artırılmasına yönelik çalışmalara hızlı bir şekilde yönelim başlamıştır. Sulama programlaması, bir bitkiye yetişme periyodu boyunca ne zaman ve ne kadar sulama suyu uygulanacağının belirlenmesine yönelik çalışmaları kapsar. Bu kapsamda, öncelikle yörenin iklim, toprak, topografya ve bitki özelliklerine uygun mevcut suyun etkin olarak kullanılacağı, verim azalması yaratmayacak bir sulama yönteminin seçilmesi gerekmektedir. Sulama yöntemleri içerisinde, damla sulama yöntemi; yüksek randıman, üniform su kullanımı ve işletme kolaylığı bakımından, özellikle sebze ve meyve ağaçlarının sulanmasında ön plana çıkmaktadır. Günümüzde, İsrail'in sulu tarım alanlarının tamamı, İspanya'nın \%74'i, Fransa'nın \%62'si ve Amerika Birleşik Devletleri'nin \%57'si damla sulama yöntemini içerisine alan basınçlı sulama yöntemleri ile sulanmaktadır. Ülkemizde ise basınçlı sulama uygulamalarının yaklaşık \%18 civarında olduğu varsayılmasına karşın son yıllarda kullanımı giderek artmaktadır (ICID, 2012).

Trakya Bölgesi, ülkemizin önemli tarımsal bölgelerinden birisi olup, ayçiçeği ülke üretiminin \%35'ini ve buğday üretiminin ise \%12'sini sağlamaktadır. Fakat, bölgedeki hızlı sanayileşme nedeniyle tarım alanlarının azalması ve birim alandan elde edilecek üretim artışı zorunluluğundan dolayı alternatif bitki desenleri arayışı hızlanmıştır. Bölgede ayçiçeği ve buğday tarımı kuru koşullarda yapılmasına karşın, ilkbahar yağışlarının düzenli olması nedeniyle her iki bitkiden de elde edilen birim alan verimleri ülke ortalamasının üstündedir. Ayrıca, iki bitki yetiştirme periyodu arasında kalan sürede, özellikle Haziran-Temmuz aylarındaki buğday hasadından sonra, Nisan-Mayıs aylarında ki ayçiçeği ekimine kadar yaklaşık 8 ay boş kalan tarım arazilerinde, sulu koşullar altında yetişebilecek bitki alternatifleri üretilmeli ve entansif tarımın bölgede kullanılabilirliği ortaya çıkarılmalıdır. Bu alternatiflerden birisi olarak, yetiştirme periyodu kısalığı ile uygunluğu ve pazarlanabilir özelliklerden dolayı sebze yetiştiriciliği tercih edilebilir.

Patlıcan, vitamin ve mineral içeriği bakımından oldukça zengindir. Bu nedenle ülkemiz de dahil pek çok ülkede büyük ekonomik değere sahiptir. İstatistiklere göre Solanaceae familyası içerisinde üretim bakımından patates ve domatesten sonra üçüncü önemli sebzedir (Doğanlar ve ark. 2002, Çolak ve ark. 2017). FAO'nun verilerine göre dünyada patlıcan üretimi ortalama olarak 48,4 milyon tondur. Ülkemiz patlıcan yetiştiriciliği yapılan ülkeler içerisinde üretim bakımından 880 bin ton ile önemli bir yere sahiptir (FAO, 2015). Ülkemiz patlıcan yetiştiriciliği yapılan ülkeler içerisinde üretim bakımından üçüncü sırada olup, dünya üretiminin \%3'ünü karşılamaktadır. Ülkemizin bütün bölgelerinde patlıcan yetiştiriciliği yapılmakla birlikte yoğunluk, 2015 yılı verilerine göre en fazla patlıcan üretimi 392000 ton ile Akdeniz bölgesindedir (Anonim, 2015).

Patlıcan bitkisinin farklı sulama suyu koşullarında su tüketimi, su kullanım randımanlarının, vejetatif gelişme ve verim parametrelerinin belirlenmesine yönelik ülkemizde ve dünyada yürütülmüş birçok bilimsel araştırmalar bulunmaktadır (Kırnak ve ark. 2002. Ertek ve ark. 2006, Karam ve ark. 2011, Pirboneh ve ark. 2012, Çolak ve ark. 2017, Cemek ve ark., 2018). Bu araştırmalarda genel olarak patlıcan bitkisinden elde edilen verim değerlerinin uygulanan sulama suyu miktarına göre değiştiğini belirtmişlerdir. Bu çalışmada ise Trakya Bölgesi için tarımsal üretimde buğday-ayçiçeği münavebe sisteme alternatif olabilecek patlıcan yetiştiriciliğinde farklı sulama suyu uygulamaları altında su tüketimi, su kullanım randımanı ve verim değerlerinin eldesi amaçlanmıştır. Araştırma, Tekirdağ Bağcılık Araştırma Enstitüsü arazisinde 2015 ve 2016 yıllarında yürütülmüştür. Elde edilen tüm değerlerin, Trakya Bölgesi koşullarında patlıcan bitkisinin su kullanımına yönelik ilk çalışma olması açısından önemlidir.

\section{Materyal ve Yöntem}

Araştırma, Tekirdağ il merkezine 2.5 km uzaklıkta yer alan Tekirdağ Bağcılık Araştırma Enstitüsü Müdürlüğü arazisinde yürütülmüştür. Araştırma alanının denizden yüksekliği ortalama $4 \mathrm{~m}$, enlem derecesi $40^{\circ} 59^{\prime}$ kuzey, boylam derecesi ise $27^{\circ} 29^{\prime}$ doğudur. Araştırma alanı yarı kurak bir iklim kuşağı içinde yer almaktadır. Uzun yıllar ortalamalarına göre, yıllık ortalama sıcaklık $13.9^{\circ} \mathrm{C}$ 'dir. Aylık sıcaklık ortalamaları açısından en soğuk ay $4.7^{\circ} \mathrm{C}$ ile Ocak, en sıcak ay ise $23.8^{\circ} \mathrm{C}$ ile Temmuz aylarıdır. Yıllık ortalama yağış miktarı $580.8 \mathrm{~mm}$ olmasına karşın, bunun büyük bir kısmı Ekim ile Nisan ayları arasındaki dönemde gerçekleşmektedir. Yıllık ortalama bağıl nem \% 76.9' dur. Yıllık ortalama rüzgâr hızının 2 m yükseklikteki değeri $2.90 \mathrm{~m} / \mathrm{s}$ 'dir.

Araştırmanın yürütüldüğü Tekirdağ Bağcılık Araştırma Enstitüsü Müdürlüğü toprakları hafif tuzlu, az kireçli 
ve organik madde içeriği düşük killi tınlı bünyeye sahip topraklardan oluşmaktadır. Alanda eğim batıdan doğuya doğrudur. Eğim batı kesimlerde oldukça yüksek olup \%15 dolayında, doğu kesimlerde ise \%1.5 civarındadır. Araştırma alanında iki farklı profilden alınan toprakların fiziksel özellikleri; tarla kapasitesi, solma noktası, bünye sınıfı, hacim ağırlığı ve kullanılabilir su tutma kapasitesi değerlerinin ortalaması Çizelge 1'de verilmiştir. Araştırma alanının toprak bünye sınıfı kil veya killi-tın, kullanılabilir su tutma kapasitesi $77.62 \mathrm{~mm} / 60 \mathrm{~cm}$ ve $120.12 \mathrm{~mm} / 90$ $\mathrm{cm}$ olarak hesaplanmıştır. Çift silindir infiltrometre ölçmeleri sonucunda toprağın infiltirayon hızı değeri ortalama olarak $12 \mathrm{~mm} / \mathrm{h}$ alınmıştır. Sulama suyu kalite sınıfı $\mathrm{T}_{2} \mathrm{~S}_{1}$ olarak belirlenmiştir ve sulama suyu analiz sonuçlarının bitki gelişmesini olumsuz etkileyecek özelliklerde olmadığı görülmektedir. Damlatıcı debisi $4 \mathrm{~L} / \mathrm{h}$, damlatıcı aralığı ise $0.45 \mathrm{~m}$ olarak topraklarının bünye sınıfı ve gerçek infiltrasyon hızı değerlerine göre seçilmiştir.

Çizelge 1. Araştırma alanı topraklarının fiziksel özellikleri

Table 1. The physical characteristics of soil at the experimental site

\begin{tabular}{|c|c|c|c|c|c|c|c|}
\hline \multirow{2}{*}{$\begin{array}{l}\text { Profil } \\
\text { Derinliği } \\
(\mathrm{cm})\end{array}$} & \multirow{2}{*}{$\begin{array}{l}\text { Bünye } \\
\text { sinıfi }\end{array}$} & \multicolumn{2}{|c|}{ Tarla kapasitesi } & \multicolumn{2}{|c|}{ Solma noktası } & \multirow{2}{*}{$\begin{array}{l}\text { Hacim } \\
\text { A ğırlı̆ } \\
\left(\mathrm{g} / \mathrm{cm}^{3}\right)\end{array}$} & \multirow{2}{*}{$\begin{array}{l}\text { Kullanılabilir } \\
\text { su tutma } \\
\text { kapasitesi } \\
(\mathrm{mm})\end{array}$} \\
\hline & & $\%$ & $\mathrm{~mm}$ & $\%$ & $\mathrm{~mm}$ & & \\
\hline $0-30$ & Killi-tın & 26.01 & 116.26 & 17.91 & 80.06 & 1.49 & 36.20 \\
\hline $30-60$ & Killi-tın & 28.45 & 134.85 & 19.71 & 93.43 & 1.58 & 41.42 \\
\hline $60-90$ & Kil & 31.76 & 153.40 & 22.96 & 110.90 & 1.61 & 42.50 \\
\hline $\begin{array}{l}0-60 \\
0-90\end{array}$ & & & $\begin{array}{l}251.11 \\
404.51\end{array}$ & & $\begin{array}{l}173.49 \\
284.39\end{array}$ & & $\begin{array}{c}77.62 \\
120.12\end{array}$ \\
\hline
\end{tabular}

Araştırmada patlıcan (Solanum melongena L.) çeşidi olarak yuvarlak oval (Bsotan Tip) adı verilen çeşit kullanılmıştır. Yuvarlak oval patlıcan çeşidinde yapraklar dik ve kuvvetli, meyveler iyi şekilli ve parlak koyu mor renklidir. Meyve uzunlukları 30 cm'ye kadar çikabilir (Aybak 2005, Şalk ve ark., 2008). Araştırma, tesadüf bloklarında deneme deseninde üç tekerrürlü olarak yürütülmüştür ve deneme konuları rastgele dağıtılmıştır (Yurtsever, 1984). Araştırmada deneme konuları, bölge koşulları ve çiftçi uygulamaları dikkate alınarak seçilen ortalama A sınıfı buharlaşma kabından 5 gün sulama aralığında ölçülen açık su yüzeyi buharlaşma miktarının farklı oranlarının uygulanması şeklinde oluşturulmuştur.

Deneme konular1;

I $_{1}$ konusu: Toplam buharlaşma miktarının \%125'inin uygulandığı sulama uygulaması,

I 2 konusu: Toplam buharlaşma miktarının \%100'ünün uygulandığı sulama uygulaması,

$\mathrm{I}_{3}$ konusu: Toplam buharlaşma miktarının \%75'inin uygulandı̆̆ı sulama uygulaması,

$\mathrm{I}_{4}$ konusu: Toplam buharlaşma miktarının \%50’sinin uygulandığı sulama uygulaması,

biçiminde düzenlenmiştir.

Deneme alanı $17.40 * 11.20 \mathrm{~m}$ boyutlarında olup toplam $194.88 \mathrm{~m}^{2}$ 'dir. Oluşturulan 3 bloğun her birinde 4 adet olmak üzere toplam 12 adet parsel bulunmaktadır. Bir deneme parseli $2.4 * 2.8 \mathrm{~m}$ boyutlarında olmak üzere toplam $6.72 \mathrm{~m}^{2}$ alana sahiptir. Bir deneme parselinde 4 adet bitki sırası bulunmaktadır. Patlıcan fideleri deneme parsellerine 2015 yılında 27 Mayıs, 2016 yılında ise 20 Mayıs tarihinde bitki sıra aralığ $10.60 \mathrm{~m}$ sıra üzeri ise 0.40 m olacak şekilde dikilmiştir. Tüm parsellerde birer bitki sırası kenar etkisi göz önüne alınarak hasat parseli dışında bırakılmıştır. Böylece hasat parseli $1.20 * 2.00 \mathrm{~m}$ olmak üzere toplam $2.40 \mathrm{~m}^{2}$ olmuştur. Her deneme parselindeki bitki sayısı 28, hasat parselinde ise 10 adettir. Parsellerin düzenlenmesi sırasında, sulamalarda sızma yoluyla oluşabilecek yan etkileri önlemek amacıyla parseller arasında ve bloklar arasında $3.00 \mathrm{~m}$ boşluk bırakılmıştır.

Denemede kullanılan sulama suyu Enstitüde bulunan dereden ve kuyudan sağlanmış, su önce havuzda toplanmış, bir pompa yardımıyla alana iletilmiş ve uygulama damla sulama yöntemiyle gerçekleştirilmiştir. Depolama havuzundan pompa ile alınan sulama suyu, hidrosiklon, kum-çakıl filtre tankı ve disk elek filtre bulunan 
kontrol biriminden geçtikten sonra 6 atm işletme basınçlı, $50 \mathrm{~mm}$ dış çaplı sert PE borular yardımı ile araştırma alanına iletilmiştir. Ayrıca, sistemde oluşan basıncı kontrol etmek amacıyla manometreler yerleştirilmiştir. Her bir deneme parseli için manifold boru hatları $32 \mathrm{~mm}$ dış çaplı sert PE borulardan oluşturulmuştur. Deneme parselleri içerisinde her bitki sırasına $16 \mathrm{~mm}$ dış çaplı yumuşak PE borulardan oluşan lateral boru hatları döşenmiş̧ir. Damlatıcı debisi Yıldırım (2008)'de belirtilen esaslara göre toprağın bünyesi ve infiltirasyon hızı dikkate alınarak $4 \mathrm{~L} / \mathrm{h}$ olarak seçilmiştir. Damlatıı aralı̆̆ toprağın infiltirasyon hızı ve damlatıcı debisi dikkate alınarak $45 \mathrm{~cm}$ olarak hesaplanmıştır. Böylelikle her lateral boru hattına $45 \mathrm{~cm}$ aralıklarla on-line damlatıcılar yerleştirilmiştir. Bir deneme parsellerinin ayrıntısı Şekil 1'de verilmiştir.

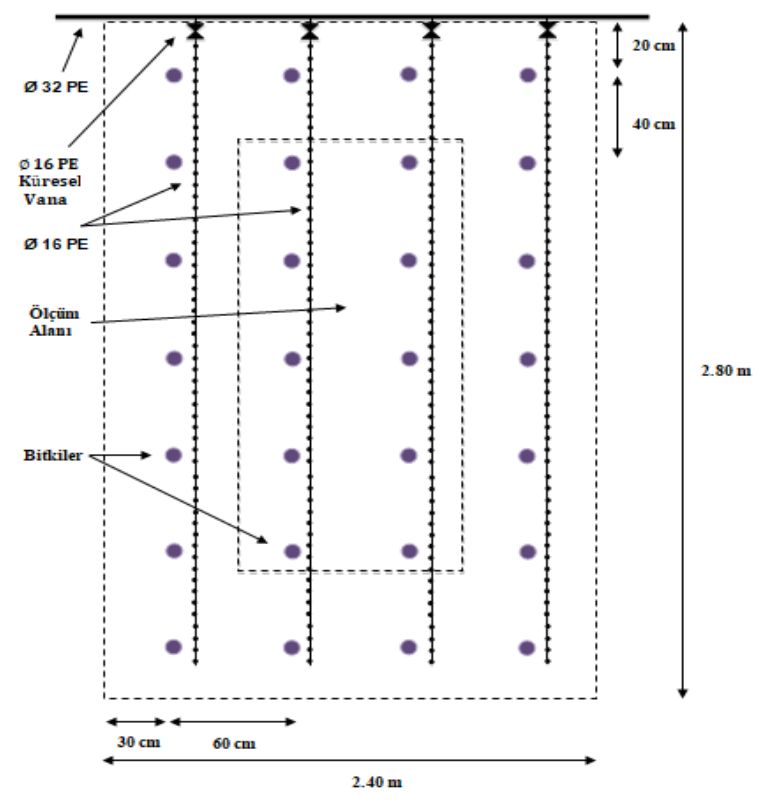

Şekil 1. Bir deneme parselinin ayrıntısı

Figure 1. Detail of a treatment plot

Deneme parsellerinde uygulanacak sulama suyu miktarları aşağıdaki eşitlik yardımıyla 5 günlük yığışımlı açık su yüzeyi buharlaşma değerleri kullanılarak hesaplanmıştır (Kanber ve ark. 2004).

$\mathrm{I}=\mathrm{K}_{\mathrm{pc}} \times \mathrm{E}_{\mathrm{p}} \times \mathrm{P}$

Eşitlikte; I: uygulanacak sulama suyu miktarı $(\mathrm{mm}), \mathrm{K}_{\mathrm{pc}}$ : buharlaşma kabına bağlı katsayı, $\mathrm{E}_{\mathrm{p}}$ : yığışımlı buharlaşma miktarı, (mm), P: lateral aralığı ve damlatıcı aralığı göre belirlenen sslatılan alan yüzdesi (\%), dir. Islatılan alan yüzdesi damlatıcı aralığı ve lateral aralığına göre \%75 olarak hesaplanmıştır.

Bitki su tüketimi değerleri, bitki etkili kök derinliğine göre aşağıda verilen su bütçesi yaklaşımı ile hesaplanmıştır (Walker ve Skogerboe 1987). Bu amaçla, sulama uygulaması öncesi her bir deneme konusunda iki adet parselde $90 \mathrm{~cm}$ toprak derinliğinde $30 \mathrm{~cm}$ 'lik toprak katmanları için kuru ağırlık yüzdesine göre toprak nemi ölçülmüştür.

$\mathrm{ET}=\mathrm{I}+\mathrm{P}+\mathrm{C}_{\mathrm{p}}-\mathrm{D}_{\mathrm{p}} \pm \mathrm{R}_{\mathrm{f}} \pm \Delta \mathrm{S}$

Eşitlikte; ET: Bitki su tüketimi (mm), I: periyot boyunca uygulanan sulama suyu miktarı (mm), P: periyot boyunca düşen yağı̧̧ $(\mathrm{mm}), \mathrm{C}_{\mathrm{p}}$ : kök bölgesine kılcal yükselişle giren su miktarı $(\mathrm{mm}), \mathrm{D}_{\mathrm{p}}$ : derine sızma kayıpları $(\mathrm{mm}), \mathrm{R}_{\mathrm{f}}$ : deneme parsellerine giren ve çıkan yüzey akış miktarı $(\mathrm{mm}), \Delta \mathrm{S}$ : kök bölgesindeki toprak nemindeki değişimler (mm), değerlerini göstermektedir.

Çalışma alanında taban suyu problemi bulunmadığından, bitki kök bölgesine kılcal hareketle su girişi olmadığı varsayılarak $\mathrm{C}_{\mathrm{p}}$ değeri göz önüne alınmamıştır. Ayrıca, yüzey akış miktarları basınçlı sulama sistemi kullanıldığından hesaplara katılmamışıtır (Kanber 1997). Derine sızma kayıpları için bir alt katman izlenmiştir.

Her bir deneme parselinde hasat işlemleri 2015 yılında 5 Ekim, 2016 yılında ise 7 Eylül tarihlerinde sonlandırılmıştır. Her bir parselde ölçüm bitkilerinde bitki boyu, bitki gövde çapı, meyve eni, meyve boyu ve toplam verim değerleri belirlenmiştir. Bitki boyu değerleri sulama sezonu bittiğinde mira yardımıyla her bir 
parselde 10 adet bitkide $\mathrm{cm}$ cinsinden ölçülmüştür. Bitki gövde çapı değerleri ise toprak yüzeyinden yaklaşı $5 \mathrm{~cm}$ yukarıdan kumpas yardımıyla ölçülmüsşür. Hasat edilen patlıcan meyvelerinden her bir parselden rastgele seçilen 10 adedinde meyve eni ve meyve boyu değerleri belirlenmiştir. Ayrıca parsellerden elde edilen verim değerlerine göre toplam verim değerleri hesaplanmıştı. Deneme konularından elde edilen patlıcan gelişim ve verim parametreleri arasındaki farklılıkların düzeyinin belirlenmesinde varyans analizi, farklılıkların sınıflandırılmasında ise LSD testi kullanılmıştır. Elde edilen veriler Yurtsever (1984)'de açıklanan esaslara göre değerlendirilmiş̧ir.

Deneme konularına uygulanan sulama suyu, ölçülen bitki su tüketimi ve hasat verimlerine göre, sulama suyu kullanım ve su kullanım randımanı değerleri aşağıdaki eşitlikler yardımı ile hesaplanmıştır (Zhang ve ark. 1999).

$$
\begin{aligned}
& \text { IWUE }=\frac{Y}{I} \\
& \text { WUE }=\frac{Y}{F T}
\end{aligned}
$$

Eşitliklerde; IWUE: Sulama suyu kullanım randımanı $\left(\mathrm{kg} / \mathrm{m}^{3}\right)$, WUE: su kullanım randımanı $\left(\mathrm{kg} / \mathrm{m}^{3}\right), \mathrm{Y}$ : deneme konularından ölçülen hasat verimi (t/ha), I: uygulanan sulama suyu miktarı (mm), ET: ölçülen bitki su tüketimi (mm)'dir.

\section{Bulgular ve Tartışma}

Deneme konularına dikim işlemini takiben birinci yıl $10 \mathrm{~mm}$, ikinci yıl $15 \mathrm{~mm}$ can suyu uygulaması yapılmış̧ır. Deneme konularına, ortalama 5 gün ara ile can suyu hariç birinci yıl 20, ikinci yıl 19 kez sulama uygulaması yapılmıştır. Deneme sonucunda uygulanan toplam sulama suyu miktarları, 2015 yılında deneme konularına göre 283.0 ile $693.0 \mathrm{~mm}$ arasında, 2016 yılında ise 293.0 ile $711.5 \mathrm{~mm}$ arasından değişmiştir. Denemenin her iki yılında deneme konularına göre uygulanan sulama suyu miktarları hemen hemen aynı olmuştur. Her bir deneme konusunda sulama uygulamaları öncesinde $90 \mathrm{~cm}$ toprak derinliğinde ölçülen nem değerleri 2015 yılı için Şekil 2'de ve 2016 yılı için Şekil 3'de verilmiştir. Şekillerden görüleceği gibi uygulanan sulama suyuna bağglı olarak ölçülen nem miktarlarında azalış daha fazla olmuştur. Denemenin birinci yılında $\mathrm{I}_{1}$ deneme konusunda sulama sezonu öncesinde ölçülen toprak nem değerlerinin ortalama olarak kullanılabilir su tutma kapasitesinin \%47'si seviyelerinde $\mathrm{I}_{4}$ deneme konusunda ise $\% 58$ seviyelerinde olduğu görülmüştür. Denemenin ikinci y1lında ise bu seviyelerinin \%50 ile \%57 aralığında olduğu belirlenmiştir.

Tüm deneme konularında 2015 ve 2016 yılı yetiştiricilik dönemleri içerisinde uygulanan sulama suyu miktarları, etkili yă̆ı̧ ve topraktaki nem değişimi değerlerine göre hesaplanan bitki su tüketimi değerleri Çizelge 2 'de özetlenmiş̧ir. Büyüme mevsimi boyunca deneme konularından ölçülen bitki su tüketimi değerleri 2015 y1lı için $466.2 \mathrm{~mm}$ ile $837.0 \mathrm{~mm}$ arasında, 2016 yllı için $411.7 \mathrm{~mm}$ ile $797.1 \mathrm{~mm}$ arasında değişmiştir. Bu çalışmadan elde edilen patlıcan bitkisi için toplam bitki su tüketimi değerleri ülkemizde ve dünyada yürütülen çalışmalardan elde edilen mevsimlik bitki su tüketimi değerleri ile benzerlik göstermektedir (Karam ve ark., 2011, Çolak ve ark., 2017). Uygulanan sulama suyu miktarı arttıkça ölçülen bitki su tüketimi değerleri artmıştır. A sınıfı buharlaşma kabından ölçülen buharlaşmanın \%100'ün uygulandığı $\mathrm{I}_{2}$ deneme konusundan birinci yıl $709.7 \mathrm{~mm}$, ikinci yıl ise $670.7 \mathrm{~mm}$ bitki su tüketimi ölçülmüştür. Bu deneme konusuna göre \%25 sulama suyu kısıtı yapılan ve A sınıfı buharlaşma kabından ölçülen buharlaşma miktarının \%75'inin uygulandığ $\mathrm{I}_{3}$ deneme konusunda ise birinci yıl $583.2 \mathrm{~mm}$ ile $\% 18$, ikinci yıl ise $538.2 \mathrm{~mm}$ ile $\% 20$ daha düşük bitki su tüketimi ölçülmüştür. Aynı şekilde, $\% 50$ kısıt yapılarak, A sınıfı buharlaşma kabından ölçülen buharlaşma miktarının \%50'sinin uygulandığı $\mathrm{I}_{4}$ deneme konusunda ise birinci yıl $466.2 \mathrm{~mm}$ ile $\% 34$, ikinci yıl ise $411.7 \mathrm{~mm}$ ile $\% 39$ daha düşük bitki su tüketimi hesaplanmıştır. Diğer yandan, A sınıfı buharlaşma kabından ölçülen buharlaşma miktarının \%125'inin uygulandığı $\mathrm{I}_{1}$ deneme konusunda ise $\mathrm{I}_{2}$ deneme konusuna göre birinci y1l $837.0 \mathrm{~mm}$ ile $\% 18$, ikinci yll ise $797.1 \mathrm{~mm}$ ile $\% 19$ daha fazla bitki su tüketimi ölçülmüştür.

Günlük bitki su tüketimi değerleri araştırmanın birinci yılında $\mathrm{I}_{1}$ deneme konusu için 2.1 ile $9.5 \mathrm{~mm} / \mathrm{gün}, \mathrm{I}_{2}$ deneme konusu için 1.6 ile $8.2 \mathrm{~mm} /$ gün, $\mathrm{I}_{3}$ deneme konusu için 1.7 ile $6.4 \mathrm{~mm} /$ gün ve $\mathrm{I}_{4}$ deneme konusu için 2.6 ile $5.5 \mathrm{~mm} /$ gün arasında ölçülmüştür. Denemenin ikinci yılında ise günlük bitki su tüketimi değerleri $\mathrm{I}_{1}$ deneme konusu için 4.6 ile $9.7 \mathrm{~mm} /$ gün, $\mathrm{I}_{2}$ deneme konusu için 4.3 ile $8.2 \mathrm{~mm} /$ gün, $\mathrm{I}_{3}$ deneme konusu için 3.7 ile 6.5 $\mathrm{mm} /$ gün ve $\mathrm{I}_{4}$ deneme konusu için 3.0 ile $5.2 \mathrm{~mm} /$ gün olmuştur. Günlük bitki su tüketimi değerleri genel olarak yorumlandığında, uygulanan sulama suyu miktarına göre artmış, kısıt uygulamaları, günlük sıcaklık ve güneşlenme sürelerine bağlı olarak azalmıştır. 


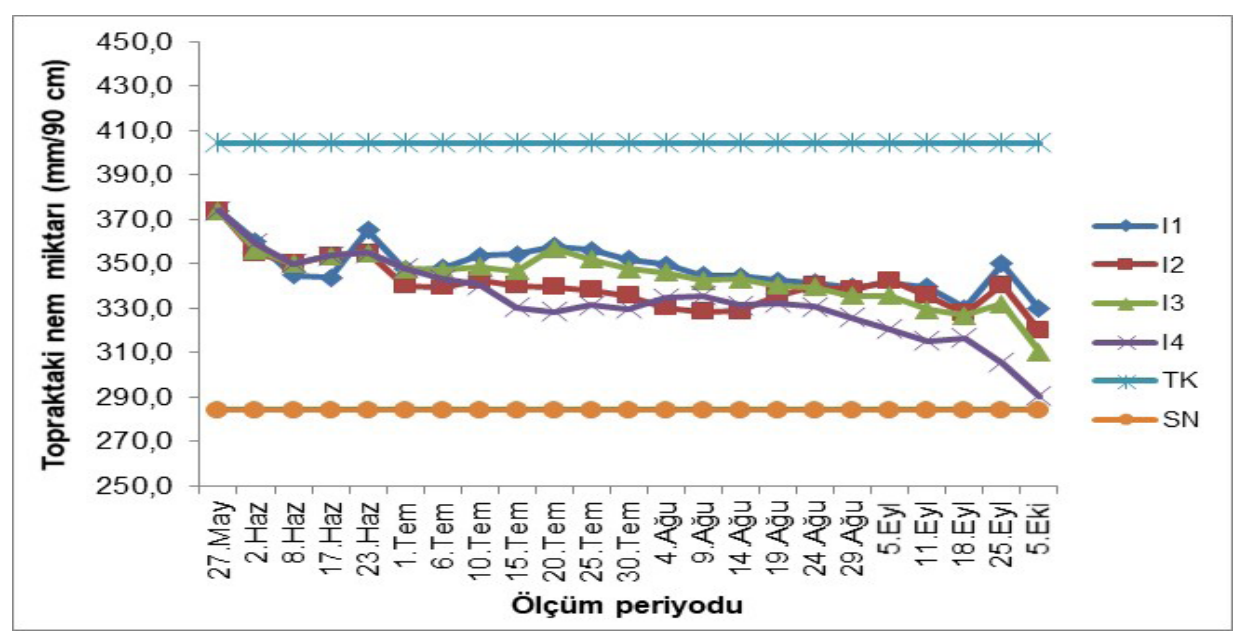

Şekil 2. Bitki gelişim periyodu boyunca sulama öncesi topraktaki nem değişimleri, (2015 yılı)

Figure 2. Moisture changes in the soil before irrigation during the plant growth period, (2015 year)

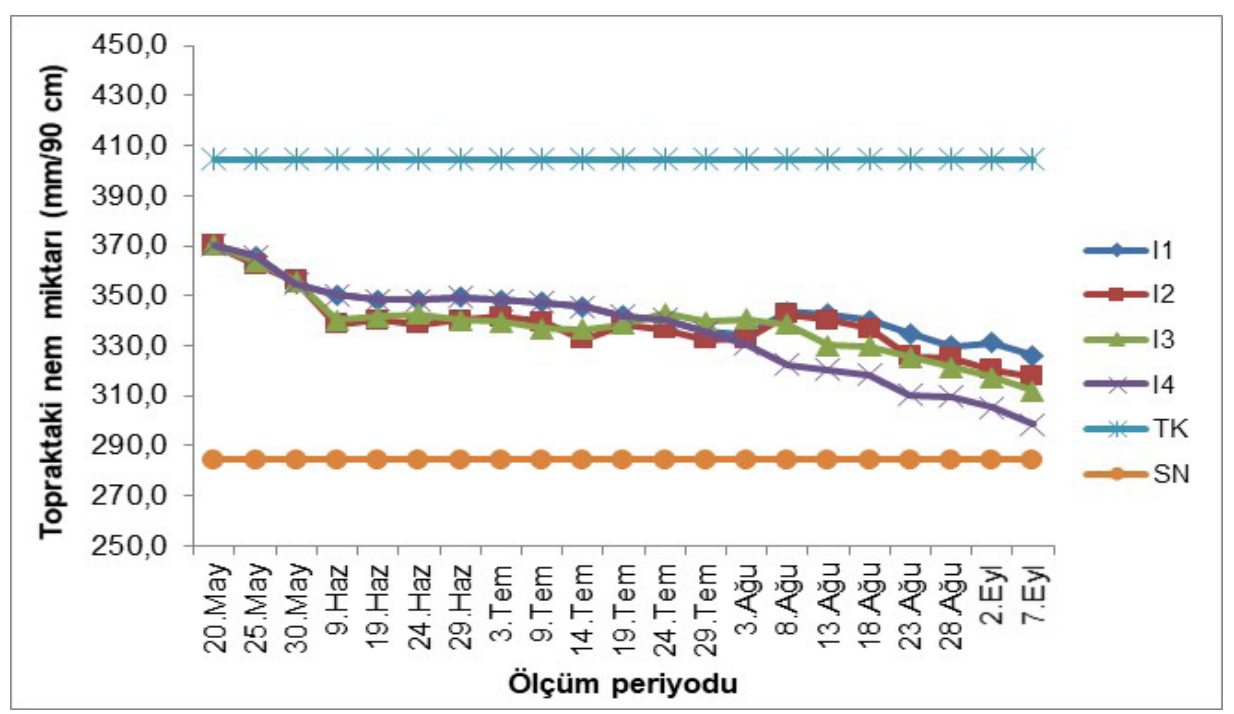

Şekil 3. Bitki gelişim periyodu boyunca sulama öncesi topraktaki nem değişimleri, (2016 yılı)

Figure 3. Moisture changes in the soil before irrigation during the plant growth period, (2016 yil)

Deneme konularından ölçülen patlıcan bitkisinin bitki boyu, bitki gövde çapı, toplam verim, meyve eni ve meyve boyu değerleri Çizelge 3 'te özetlenmiştir. Çizelgeden görüleceği gibi deneme konularında elde edilen bitki boyu değerleri denemenin birinci yılında 450 ile $494 \mathrm{~mm}$ arasında değişirken, denemenin ikinci yılında ise 400 ile $450 \mathrm{~mm}$ arasında değişmiştir. Diğer yandan bitki gövde çapı değerleri de 2015 yılı için $13.2 \mathrm{~mm}$ ile $14.9 \mathrm{~mm}$ arasında, 2016 yılı için ise $12.5 \mathrm{~mm}$ ile $13.5 \mathrm{~mm}$ arasında değişmiştir. Yapılan istatistiksel analizler sonucunda farklı sulama suyu uygulamalarının patlıcan bitkisinin vejetatif gelişme parametrelerine önemli bir etkisinin olmadığı belirlenmiştir. Deneme konularından elde edilen toplam patlıcan verimleri ise 2015 yılında 33.4 t/ha ile $47.6 \mathrm{t} / \mathrm{ha}$ arasında, 2016 yılında ise $21.8 \mathrm{t} /$ ha ile $31.9 \mathrm{t} / \mathrm{ha}$ arasında değişmiştir. Deneme yıllarında sulama suyu uygulamaları açısından en yüksek patlıcan verimleri 47.6 t/ha (2015) ve 31.90 t/ha (2016) ile A sınıfı buharlaşma kabından ölçülen değerlerin \% 125'inin uygulandığg I deneme konusundan gözlemlenmiştir. Ayrıca, her iki yılda da uygulanan sulama suyu miktarı arttıkça verim değerlerinin de arttı̆̆ belirlenmiştir. Patlıcan bitkisinin su kullanımı ve verim arasındaki ilişkilerinin belirlenmesine yönelik yürütülen çalışmalarda da benzer sonuçlar elde edilmiştir. Çolak ve ark. (2017), Çukurova koşullarında yürüttükleri araştırmada, kısıntılı sulama uygulamaları ile birlikte patlıcan verimlerinin azaldığını bildirmişlerdir. Benzer şekilde, Kırnak ve ark. 2002, Ertek ve ark. 2006, Karam ve ark. 2011, Pirboneh ve ark. 2012 tarafindan da yürütülen çalışmalarda da patlıcan bitkisinden uygulanan sulama suyu miktarlarına bağlı olarak verim değerlerinin elde edilebileceği açıklanmıştır. Deneme konularından elde 
edilen patlıcan verimleri dikkate alınarak yapılan varyans analizine göre her iki yıl içinde deneme konuları arasında toplam patlıcan verimi açısından istatistiksel olarak önemli farklar elde edilmemiştir. Deneme konularından elde edilen meyve eni değerleri 2015 yılında $106.0 \mathrm{~mm}$ ile $110.6 \mathrm{~mm}, 2016$ yılında ise $93.9 \mathrm{~mm}$ ile $98.6 \mathrm{~mm}$ arasında değişmiştir. Meyve boyu değerleri ise denemenin ilk y1lında $132.8 \mathrm{~mm}$ ile $150.9 \mathrm{~mm}$, ikinci yılında 114.2 ile 130.9 arasında değişmiştir. Verim parametreleri istatistiksel açıdan değerlendirildiğinde ise, sadece 2016 yılında farklı sulama suyu uygulamalarının meyve boyuna $\mathrm{p}<0.05$ düzeyinde etkili olduğu sonucuna varılmıştır.

Çizelge 2. Deneme konularına uygulanan sulama suyu ve ölçülen bitki su tüketimi değerleri

Table 2. Applied irrigation water and measured seasonal evapotranspiration for treatments

\begin{tabular}{cccccc}
\hline \multirow{2}{*}{$\begin{array}{c}\text { Deneme } \\
\text { y1l1 }\end{array}$} & $\begin{array}{c}\text { Deneme } \\
\text { konuları }\end{array}$ & $\begin{array}{c}\text { Topraktaki nem } \\
\text { değişimi } \\
(\mathrm{mm})\end{array}$ & $\begin{array}{c}\text { Yağış } \\
(\mathrm{mm})\end{array}$ & $\begin{array}{c}\text { Uygulanan } \\
\text { sulama suyu } \\
(\mathrm{mm})\end{array}$ & $\begin{array}{c}\text { Ölçülen bitki su } \\
\text { tüketimi } \\
(\mathrm{mm})\end{array}$ \\
\hline \multirow{3}{*}{2015} & $\mathrm{I}_{1}$ & 44.2 & & 693.0 & 837.0 \\
\cline { 2 - 6 } & $\mathrm{I}_{2}$ & 53.9 & 99.8 & 556.0 & 709.7 \\
\hline \multirow{nyyyyy}{*}{2016} & $\mathrm{I}_{3}$ & 63.4 & & 420.0 & 583.2 \\
\cline { 2 - 6 } & $\mathrm{I}_{4}$ & 83.4 & & 283.0 & 466.2 \\
\hline & $\mathrm{I}_{1}$ & 38.4 & & 711.5 & 797.1 \\
\hline & $\mathrm{I}_{2}$ & 52.5 & 47.2 & 571.0 & 670.7 \\
\hline & $\mathrm{I}_{3}$ & 78.2 & & 432.8 & 538.2 \\
\hline
\end{tabular}

Çizelge 3. Deneme konularından ölçülen patlıcan vejetatif gelişme, verim ve verim parametreleri değerleri

Table 3. The measured eggplant vegetative growth, yield and yield parameters for treatments

\begin{tabular}{ccccccc}
\hline $\begin{array}{c}\text { Deneme } \\
\text { y1l1 }\end{array}$ & $\begin{array}{c}\text { Deneme } \\
\text { konular1 }\end{array}$ & $\begin{array}{c}\text { Bitki boyu } \\
(\mathrm{mm})\end{array}$ & $\begin{array}{c}\text { Bitki gövde } \\
\text { çap1 } \\
(\mathrm{mm})\end{array}$ & $\begin{array}{c}\text { Toplam verim } \\
(\mathrm{t} / \mathrm{ha})\end{array}$ & $\begin{array}{c}\text { Meyve eni } \\
(\mathrm{mm})\end{array}$ & $\begin{array}{c}\text { Meyve boyu } \\
(\mathrm{mm})\end{array}$ \\
\hline \multirow{2}{*}{2015} & $\mathrm{I}_{1}$ & $494.0 \mathrm{~ns}$ & $14.0 \mathrm{~ns}$ & $47.60 \mathrm{~ns}$ & $110.6 \mathrm{~ns}$ & $150.9 \mathrm{~ns}$ \\
& $\mathrm{I}_{2}$ & 450.0 & 13.2 & 40.40 & 106.0 & 143.7 \\
& $\mathrm{I}_{3}$ & 463.0 & 13.5 & 34.10 & 109.0 & 137.3 \\
& $\mathrm{I}_{4}$ & 465.0 & 14.9 & 33.40 & 106.3 & 132.8 \\
\hline \multirow{2}{*}{2016} & $\mathrm{I}_{1}$ & $450.0 \mathrm{~ns}$ & $13.5 \mathrm{~ns}$ & $31.90 \mathrm{~ns}$ & $98.6 \mathrm{~ns}$ & $130.9 \mathrm{a}^{*}$ \\
& $\mathrm{I}_{2}$ & 401.0 & 13.5 & 25.70 & 94.7 & $126.2 \mathrm{a}$ \\
& $\mathrm{I}_{3}$ & 400.0 & 13.9 & 22.89 & 94.8 & $120.6 \mathrm{ab}$ \\
& $\mathrm{I}_{4}$ & 419.0 & 12.5 & 21.80 & 93.9 & $114.2 \mathrm{~b}$ \\
\hline
\end{tabular}

*: $\mathrm{p}<0.05$ düzeyinde önemli, ns: önemsiz, a,b: LSD testi grupları

Deneme konularına uygulanan sulama suyu miktarları, ölçülen bitki su tüketimi değerleri ve elde edilen birim alan verimlerinin eşitliklerde yerine konulması ile hesaplanan sulama suyu kullanım (IWUE) ve su kullanım randımanı (WUE) sonuçları Çizelge 4'te verilmiştir. IWUE değerleri denemenin ilk yılında 6.86 ile $11.80 \mathrm{~kg} /$ $\mathrm{m}^{3}$, ikinci yıl ise 4.49 ile $7.44 \mathrm{~kg} / \mathrm{m}^{3}$ arasında değişmiştir. Varyans analizi sonuçlarına göre denemenin her iki yılında da IWUE değerleri arasında istatistiksel açıdan önemli farklılıklar elde edilmiştir. Özellikle, her iki yılda da farklı sulama suyu uygulamaları konuları arasında $\mathrm{p}<0.01$ düzeyinde farklılıklar belirlenmiştir. Yapılan LSD testi sonuçlarında göre ise sulama suyu uygulamaları açısından en düşük miktarda sulama suyunun uygulandığı $\mathrm{I}_{4}$ deneme konusu en üst grubu sulama suyu uygulanan diğer deneme konuları ise en alt grubu oluşturmuştur. WUE değerleri deneme konuları arasında 2015 yılında 5.68 ile $7.16 \mathrm{~kg} / \mathrm{m}^{3}$ arasında, 2016 yılında ise 3.83 ile $5.30 \mathrm{~kg} / \mathrm{m}^{3}$ arasında değişmiş̧tir. İki yılda da en yüksek $W U E$ değerleri $\mathrm{I}_{4}$ deneme konusundan elde edilmesine karşın deneme konuları arasında istatistiksel olarak önemli düzeyde farklılık görülmemiş̧tir. 
Çizelge 4. Deneme konularından elde edilen sulama suyu ve su kullanım randımanı değerleri

Table 4. Irrigation water use efficiency and water use efficient values for treatments

\begin{tabular}{|c|c|c|c|}
\hline $\begin{array}{c}\text { Deneme } \\
\text { yilı }\end{array}$ & $\begin{array}{l}\text { Deneme } \\
\text { konuları }\end{array}$ & $\begin{array}{c}\text { Sulama suyu } \\
\text { kullanım randimanı } \\
(I W U E) \\
\left(\mathrm{kg} / \mathrm{m}^{3}\right)\end{array}$ & $\begin{array}{l}\text { Su kullanım } \\
\text { randımanı } \\
(W U E) \\
\left(\mathrm{kg} / \mathrm{m}^{3}\right)\end{array}$ \\
\hline \multirow{5}{*}{2015} & $\mathrm{I}_{1}$ & $6.86 b^{* *}$ & $5.68 \mathrm{~ns}$ \\
\hline & $\mathrm{I}_{2}$ & $7.27 \mathrm{~b}$ & 5.69 \\
\hline & $\mathrm{I}_{3}$ & $8.13 \mathrm{~b}$ & 5.85 \\
\hline & $\mathrm{I}_{4}$ & $11.80 \mathrm{a}$ & 7.16 \\
\hline & $\mathrm{LSD}_{0.01}$ & 3.333 & \\
\hline \multirow{5}{*}{2016} & $\mathrm{I}_{1}$ & $4.49 b^{* *}$ & $4.01 \mathrm{~ns}$ \\
\hline & $\mathrm{I}_{2}$ & $4.50 \mathrm{~b}$ & 3.83 \\
\hline & $\mathrm{I}_{3}$ & $5.28 \mathrm{~b}$ & 4.24 \\
\hline & $\mathrm{I}_{4}$ & $7.44 \mathrm{a}$ & 5.30 \\
\hline & $\mathrm{LSD}_{0.01}$ & 1.912 & \\
\hline
\end{tabular}

Deneme konularına uygulanan sulama suyu miktarı ve ölçülen mevsimlik bitki su tüketimi değerlerine karşılık elde edilen toplam pazarlanabilir verim değerleri Şekil 4 ve 5'de verilmiştir. Şekiller incelendiğinde denemenin yürütüldüğü her iki yılda da patlıcan bitkisine toplam büyüme mevsimi boyunca uygulanan sulama suyu ile elde edilen verimler arasında ikinci dereceden doğrusal ilişsiler bulunmuştur. Benzer şekilde patlıcan bitkisinden elde edilen verim değerleri ile tüm büyüme mevsimi boyunca ölçülen bitki su tüketimleri arasında da ikinci dereceden doğrusal ilişkiler bulunmuştur.

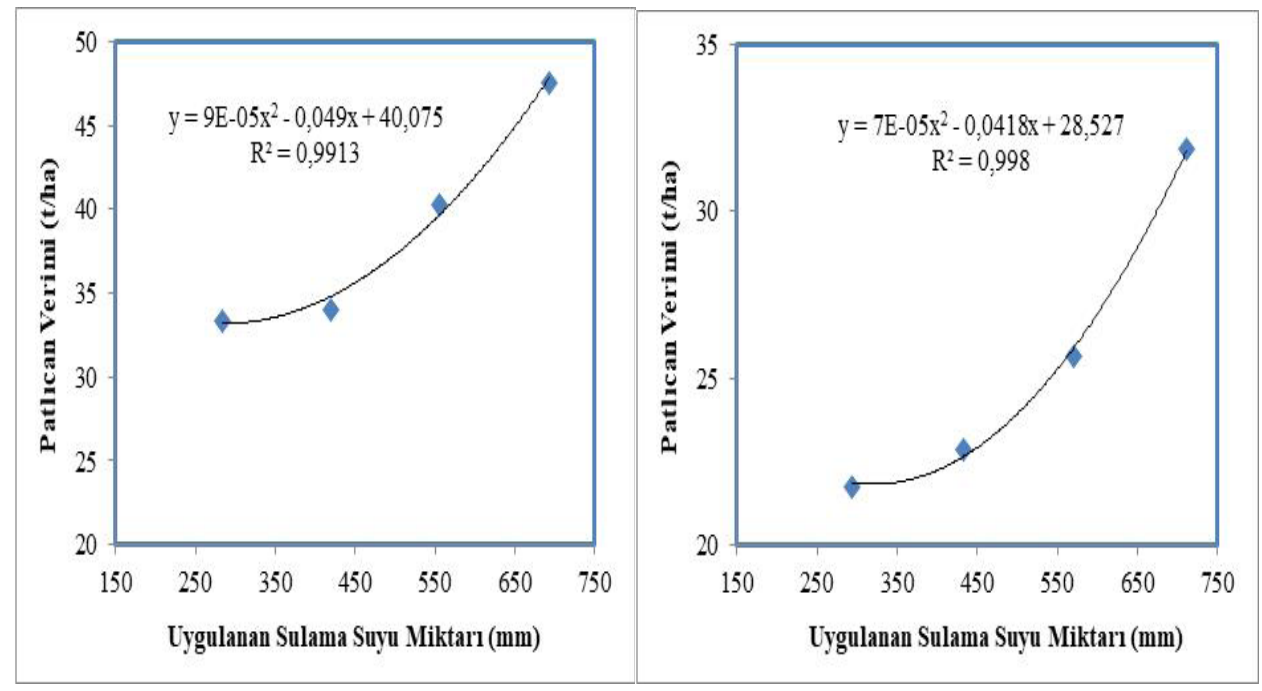

a) 2015 y1l1

b) 2016 y1lı

Şekil 4. Deneme konularına uygulanan sulama suyuna karşılık elde edilen verim grafikleri

Figure 4. The relationship between eggplant yield and seasonal water applied for treatments 


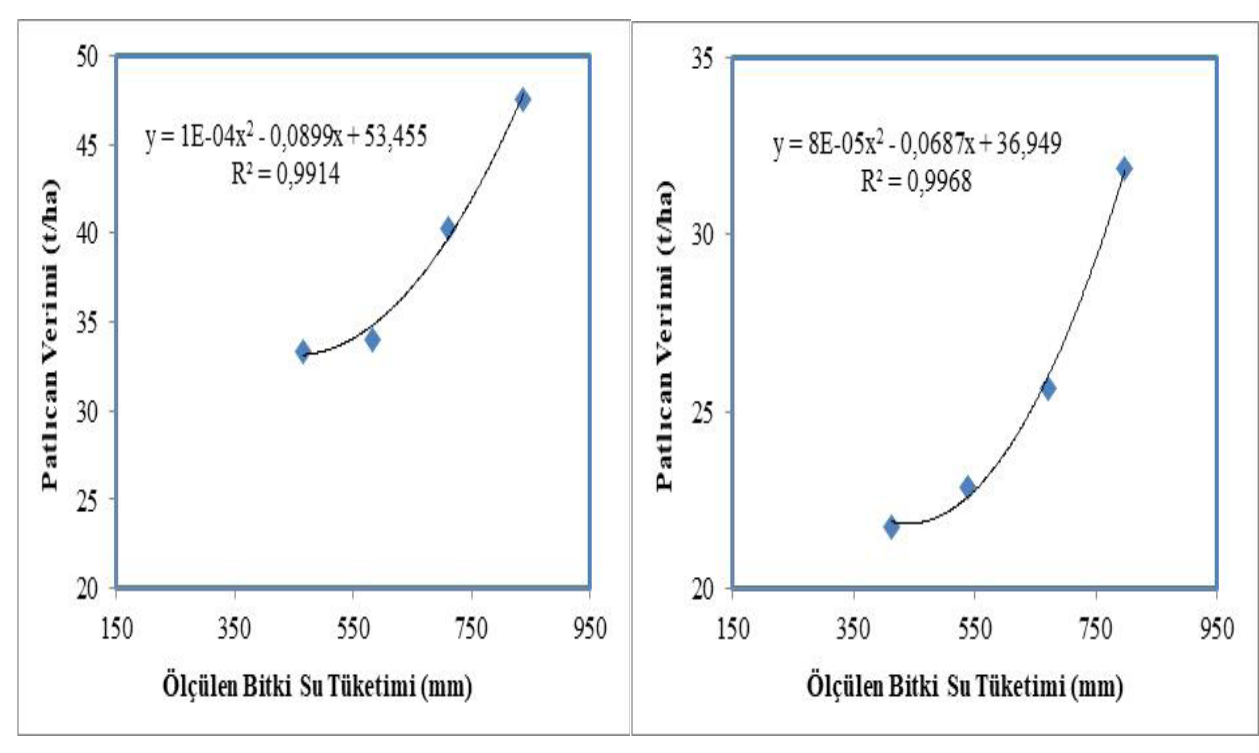

a) 2015 y1l1

b) 2016 yılı

Şekil 5. Deneme konularında ölçülen bitki su tüketimi değerlerine karşılık elde edilenverim grafikleri

Figure 5. The relationship between eggplant yield and seasonal evapotranspration for treatments

\section{Sonuç}

Damla sulama yöntemi altında farklı sulama suyu uygulamalarının patlıcan bitkisine olan etkilerinin araştırıldığı çalışma, 2015 ve 2016 yıllarında Tekirdağ koşullarında yürütülmüş̧ür. Araştırmada A sınıfı buharlaşma kabından ölçülen buharlaşma değerlerinin $\% 50,75,100$ ve $125^{\prime}$ inin uygulandığ 1 dört farklı sulama suyu uygulaması gerçekleştirilmiş̧tir. Denemenin yürütüldüğü 2015 ve 2016 yıllarında uygulanan sulama suyu miktarları ve ölçülen bitki su tüketimleri, toprak ve iklim koşullarına bağlı olarak farklılıklar göstermiştir. Araştırmanın ilk yllında tüm deneme konularına $20 \mathrm{kez}$ sulama uygulaması ile 283.0 ile $693.0 \mathrm{~mm}$ arasında sulama suyu uygulanırken, ikinci yılda ise $19 \mathrm{kez}$ sulama uygulaması ile 293.0 ile $711.5 \mathrm{~mm}$ arasında sulama suyu uygulanmıştır. Deneme konuları arasında uygulanan sulama suyu miktarları, A sınıfı kaptan ölçülen buharlaşma değerlerinin uygulama yüzdesine göre değişmiştir. En yüksek sulama suyu uygulamaları A sınıfı kaptan ölçülen buharlaşma değerlerinin $\% 125$ 'in uygulandığı deneme konusuna gerçekleştirilmiştir. Tüm büyüme mevsimi boyunca deneme konularından ölçülen mevsimlik patlıcan bitki su tüketimi değerleri 2015 yılında 466.2 ile $837.0 \mathrm{~mm}, 2016$ yılında ise 411.7 ile $797.1 \mathrm{~mm}$ arasında uygulanan sulama suyu miktarlarına bağlı olarak değişmiştir. Uygulanan sulama suyu miktarı arttıkça ölçülen bitki su tüketimi değerleri artmıştır. Deneme konuları arasında, sulama zamanı planlaması açısından önemli bir parametre olan günlük bitki su tüketimi değerleri ise uygulanan sulama suyu miktarına bağlı olarak 2015 yılında 1.6 ile $9.5 \mathrm{~mm} /$ gün ve 2016 yılında 3.0 ile $9.7 \mathrm{~mm} /$ gün arasında değişmiş̧ir.

Deneme konularının patlıcan bitkisinin vejetatif gelişim unsurlarından bitki boyu ve bitki gövde çapına etkileri istatistiksel olarak değerlendirildiğinde önemli farklar elde edilmediği belirlenmiştir. Bu sonuç, farklı sulama suyu uygulamalarının patlıcan bitkisinin vejetatif gelişim unsurlarına etkisinin olmadığı şeklinde açıklanabilir. Patlıcan bitkisinin verim ve verim unsurları açısından ise, toplam pazarlanabilir verim, meyve eni ve meyve boyu özellikleri incelenmiştir. Uygulanan sulama suyu miktarı artıkça toplam pazarlanabilir patlıcan verimi değerleri artmıştır. Deneme konularından elde edilen toplam pazarlanabilir verim değerleri, birinci yıl 33.4 ile $47.6 \mathrm{t} / \mathrm{ha}$, ikinci yıl ise 21.80 ile $31.90 \mathrm{t} / \mathrm{ha}$ arasında değişmiştir. Verim değerleri üzerine yapılan istatistiksel sonuçlar dikkate alındığında, denemenin her iki yılında da önemli farklar elde edilmemiştir. Diğer yandan, deneme konuları arasında meyve eni ve meyve boyu değerleri istatistiksel olarak değerlendirildiğinde sadece denemenin ikinci yllında meyve boyu değerleri $\mathrm{p}<0.05$ düzeyinde farklılıklar elde edilmiştir.

Verim ile uygulanan sulama suyu ve ölçülen bitki su tüketimi arasındaki ilişkiler sulama suyu kullanım randımanı ve su uygulama randımanı kavramları ile açıklanmıştır. Sulama suyu kullanım randımanı (IWUE) değerleri denemenin ilk y1lında 6.86 ile $11.80 \mathrm{~kg} / \mathrm{m}^{3}$, denemenin ikinci yılında ise 4.49 ile $7.44 \mathrm{~kg} / \mathrm{m}^{3}$ arasında değişmiştir. Su kullanım randımanı (WUE) denemenin ilk yılında 5.68 ile $7.16 \mathrm{~kg} / \mathrm{m}^{3}$, denemenin ikinci yılında ise 3.83 ile $5.30 \mathrm{~kg} / \mathrm{m}^{3}$ arasında değişmiştir. Denemenin ilk yılında elde edilen her iki randıman değerleri de verim değerlerinin yüksek olmasından dolayı daha fazla olmuştur. Randıman değerleri arasında yapılan istatistiksel 
analizlerde, sulama suyu kullanımı randımanı (IWUE) değerleri arasında her iki yılda da istatistiksel olarak $\mathrm{p}<0.01$ düzeyinde farklılıklar elde edilmiştir. Farklıların gruplandırılması sonucunda ise A sınıfı buharlaşma kabından ölçülen açık su yüzeyi buharlaşma değerlerinin \%50'sinin uygulandığı deneme konusunun ön plana çıktı̆̆ görülmüştür. 


\section{Kaynaklar/References}

Anonim. (2015). Türkiye İstatistik Kurumu Verileri, Ankara.

Aybak HÇ. (2005). Patlıcan Yetiştiriciliği. Hasad Yayıncılık. ISBN 975-8377-11-6. İstanbul.

Cemek, B.,Cantürk, A., Taşan, M. \& Taşan, S. (2018). Patlıcan Bitkisinin Sulama Programlamasının Belirlenmesinde Yapay Zeka Uygulamalarının Kullanılması. TÜBITAK Proje Sonuç Raporu, 1140538

Çolak, YB., Yazar, A., Çolak, İ., 2017. Çukurova Koşullarında toprakaltı damla yöntemiyle sulanan farklı kısıntılı sulama stratejilerinin patlican verim ve verim bileşenlerine etkisi. Alatarım, 16(1): 1-10.

Doğanlar, S., Farry, A., Daunay, M.C., Lester, R.N. \& Tanksley, S.D.,(2002). Comparative Genetic Linkage Map of Eggplant (Solanum melongena L.) and Its Implications for Genome Evolution in the Solanaceae. Genetics 161: 1697- 1711.

Ertek, A., Şensoy, S., Küçükyumuk, C. \&Gedik, I. (2006). Determination of Plant-Pan Coefficients For Field-Grown Eggplant (Solanummelongenal.) Using Class A Pan Evaporation Values. Agric. Water Manag 85: 58-66.

FAO. (2015). FAOSTAT. 'Food and Agriculture Organization of the United Nations' h http://www.fao.org/faostat/en/\#data/QC

ICID. (2012). International Commission on Irrigation and Drainage http://www.icid.org/sprinklerandmircro.pdf

Kanber, R. (1997). Sulama. Çukurova Üniversitesi Ziraat Fakültesi Ders Kitabı, Genel Yayın No. 174, Ders Kitapları Yayın No. 52, 530s, Adana.

Kanber, R., Steduto, P., Aydın, Y., Ünlü, M., Özmen, S., Çetinkökü, Ö., Özekici, B., Diker K. \&Sezen, M. S. (2004). Damla sulama sistemiyle fertigasyon uygulamalarının antepfıstığında gelişme, verim ve periyodisiteye etkisinin incelenmesi. Tübitak, TARP 1825.

Karam, F., Saliba, R., Skaf, S., Breidy, J., Rouphael, Y. \& Balendonck J. (2011). Yield and water use of eggplants (solanum melongena L.) under full and deficit irrigation regimes. Agric. Water Manag. 98: 1307-1316.

Kırnak, H., Taş, İ., Kaya, C. \& Higgs, D. (2002). Effects of deficit irrigation on growth, yield and fruit quality of eggplant under semi- arid conditions. Aust. J. Agric. Res. 53: 1367-1373.

Pirboneh, H., Ghasemi, M., Gohari, A.A., Bahari, B. \& Bazkiyaei, Z.B. (2012). Effect of Irrigation and Straw Mulch on Yield Components of Eggplant (Solanum Melongena L.). International Research Journal of Applied and Basic Sciences, Vol., 3 (1), $46-51$.

Salk, A., Arın, L., Deveci, M. \& Polat, S. (2008). Özel Sebzecilik. Namık Kemal Üniversitesi Ziraat Fakültesi Bahçe Bitkileri Bölümü Ders Kitabı. ISBN 978-9944-0786-0-3. Tekirdağ.

Walker, W.R., \& Skogerboe, G. V. (1987). Surface Irrigation. Theory and Practice. Prentice- Hall, Englewood Cliffs, 375pp, New Jersey

Yıldırım, O. (2008). Sulama Sistemlerinin Tasarımı. Ankara Üniversitesi Ziraat Fakültesi Yayın No: 1565, Ankara.

Yurtsever, N. (1984). Deneysel İstatistik Metotları. Köy Hizmetleri Genel Müd. Yayınları No. 56, Ankara.

Zhang, H., Wang X., You, M. \& Liu, C.(1999). Water -yield relations and water-use efficiency of winter wheat in THE North China Plain. Irrig Sci.19: $37-45$. 